\title{
Acceso a la información pública: los desafíos del Consejo de la Transparencia
}

Este comentario, junto a los documentos que analiza, está disponible en www.anuariocdh.uchile.cl

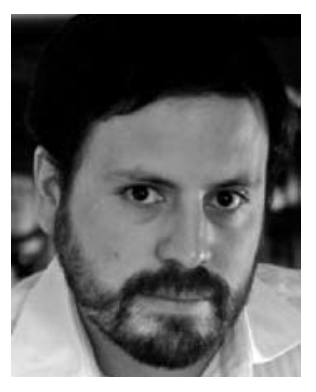

\section{Cristóbal Tello E.}

Director Ejecutivo de Chile Transparente. Abogado. MSc in Development Studies London School of Economics (LSE).

ctello@chiletransparente.cl



\section{Marcelo Cerna G.}

Jefe de Estudios de Chile Transparente. Abogado. Master of Laws - Washington College of Law (WCL), American University.

mcerna@chiletransparente.cl

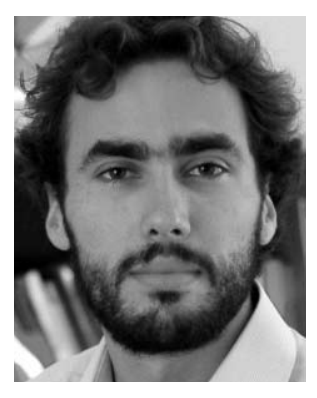

\section{Andrés Pavón $\mathrm{M}$.}

Investigador de Chile Transparente. Abogado, Universidad Alberto Hurtado. apavon@chiletransparente.cl

\section{RESUMEN}

Los autores analizan la evolución de la regulación del derecho de acceso a la información en Chile desde 1990 a la fecha, identificando las tensiones que ésta ha conocido durante la discusión políticolegislativa. Posteriormente, advierten de los principales desafíos que deberá enfrentar el Consejo para la Transparencia en la implementación de la ley. 


\section{Introducción}

La ley N²0.285 sobre Acceso a la Información Pública (en adelante, LAIP) -vigente a partir del 20 de abril de 2009- responde a los estándares internacionales más avanzados sobre normativa de acceso a la información, y posiciona a Chile entre los países de vanguardia en esta materia.

Sin perjuicio de lo anterior, la aprobación de esta legislación no es el resultado de la convicción de los actores políticos sobre la necesidad de garantizar el acceso a la información, sino que constituye una respuesta gubernamental a los casos de corrupción que han afectado al sector público en los últimos años. En consecuencia, esta nueva institucionalidad se implementará en el contexto de un sector público en cuya gestión y organización todavía predomina la cultura del secretismo.

La LAIP creó el Consejo para la Transparencia, órgano autónomo cuyo rol será clave en la aplicación adecuada y efectiva de las garantías y obligaciones establecidas en este cuerpo legal. En la implementación de esta ley el Consejo deberá enfrentar tanto los desafíos de una cultura basada en el secretismo, así como las complejidades y retos que establece la propia ley.

Este artículo analiza, en su primera parte, la evolución del derecho de acceso a la información pública en Chile y, en la segunda, los principales desafíos que deberá enfrentar la nueva institucionalidad creada por la LAIP.

\section{Evolución del derecho de acceso a la información pública en Chile}

Desde 1990 Chile ha experimentado significativos avances en la garantía del acceso a la información pública. De igual forma que en el resto de los países de Latinoamérica, los avances en políticas y normas sobre el derecho de acceso a la información pública tienen su origen en diversos factores: (i) la respuesta a las violaciones de derechos humanos en el marco del "derecho a la verdad" $^{1}$; (ii) la incorporación en la agenda pública de nuevas demandas ciudadanas que requerían acceder a la información en poder del Estado, tales como la defensa del medio ambiente, la protección del consumidor y la libertad de prensa ${ }^{2}$; (iii) y, desde 1994 hasta nuestros días, la lucha contra la corrupción.

Desde principios de los 90 los escándalos de corrupción pública en Chile motivaron la creación por parte del Poder Ejecutivo de comisiones ad hoc, cuya misión era elaborar propuestas de po-

\footnotetext{
Según Abramovich y Courtis, respecto del tratamiento de este derecho en Argentina, "uno de los desarrollos más recientes en materia de investigación de las violaciones a los derechos humanos cometidas en la pasada dictadura consiste en la conceptualización del llamado 'derecho a la verdad', es decir, el derecho de familiares de personas desaparecidas a conocer el destino de éstas, independientemente de las posibilidades de persecución penal". Al respecto, la Comisión Interamericana de Derechos Humanos señaló (caso Castillo Páez) que existiría una violación del "derecho a la verdad y a la información, debido al desinterés del Estado para esclarecer los hechos que dan lugar a este caso". ABRAMOVICH, V. y COURTIS, C. El Acceso a la Información como Derecho. En: GONZÁLEZ F. y VIVEROS F. Igualdad, Libertad de Expresión e Interés Público, Cuadernos de Análisis Jurídico, № 10, Universidad Diego Portales, 2000, p. 203.

2 La historia de la legislación nacional sobre el acceso a la información es ilustrativa sobre este último punto. Aun cuando la primera regulación del acceso a la información pública data de 1999, ya en 1994 la Ley 19.300 de Bases Generales del Medio ambiente establecía en su artículo 28 normas sobre acceso a la información ambiental y causales de reserva de la misma, encomendando a la Comisión Nacional del Medio Ambiente mantener un sistema de transparencia activa sobre una parte de la información ambiental (artículo 70). En igual sentido, en 1997 la Ley Nº 19.496 sobre protección de los derechos del consumidor consagraba expresamente el "derecho a una información veraz y oportuna sobre los bienes y servicios ofrecidos, su precio, condiciones de contratación y otras características relevantes de los mismos, y el deber de informarse responsablemente de ellos" (artículo 3, letra b); y entregaba una definición de "información básica comercial", la que debía "suministrarse obligatoriamente al público consumidor" "asegurando un acceso claro, expedito y oportuno" (artículo $1^{\circ}, \mathrm{N}^{\circ} 3$ ).
} 
líticas y cambios normativos ${ }^{3}$. El trabajo de estas comisiones impulsó el debate legislativo sobre acceso a la información pública.

La primera de estas comisiones, la Comisión Nacional de Ética Pública de 1994, recomendó legislar sobre acceso a la información pública en Chile. Sin embargo, no sería sino hasta el año 2008 cuando finalmente se aprobara una normativa de estas características.

El primer proyecto sobre acceso a la información administrativa fue presentado por el Ejecutivo en 1995. Este proyecto contenía muchas de las materias que fueron incorporadas al sistema jurídico por primera vez a través de la LAIP. Entre éstas, (i) la consagración del principio rector del "libre acceso a los documentos que se encuentren en poder de la Administración del Estado"; (ii) causales de reserva de la información, (iii) un procedimiento de acceso a la información administrativa; $y$, (iv) normas sobre transparencia activa ${ }^{4}$.

Este proyecto de ley no tuvo acogida en el Congreso, y fue enviado sin informes al archivo legislativo en marzo de 1998. Resulta esclarecedor lo expresado por el entonces senador Viera-Gallo, quien señaló que este proyecto no prosperó "porque se consideró que extremaba el principio de transparencia y publicidad", ya que "acorde con nuestra idiosincrasia, es menester preservar un equilibrio entre lo que las personas tienen derecho a saber y los documentos o debates internos de los órganos del Estado que no es conveniente que trasciendan a la opinión pública". Planteando como alternativa "que cada organismo pudiera determinar en forma autónoma los casos en que la actuación o documento debe mantenerse en reserva", ya que "entregar esta misión a la ley, agregó, ofrece el riesgo de que ésta sea tachada de inconstitucional por ser restrictiva, con lo cual se llega a un grado de transparencia completa de los órganos del Estado, para lo cual, en su opinión, nuestro país no está preparado" ${ }^{5}$.

El comentario antes citado refleja la noción -generalizada en aquel tiempo- de que la publicidad y el acceso a la información formaban parte de los "principios de buena administración", cuya extensión debía ser determinada discrecionalmente por la administración. Esta perspectiva tuvo su recepción normativa el 2001 en el Decreto Supremo № 26, del Ministerio Secretaría General de la Presidencia. Este Decreto estableció el primer "reglamento sobre el secreto o reserva de los actos y documentos de la administración del Estado", el cual transformó el secreto en la regla general en la administración pública.

No fue sino hasta el 2005, y con motivo de una segunda recomendación de la Comisión Nacional de Ética Pública, que se incorporó a la Constitución el principio de probidad y publicidad en la función pública. Esta modificación permitió garantizar la publicidad de los actos, procedimientos y fundamentos de las decisiones de los órganos del Estado, sin perjuicio de las excepciones constitucionales que justifiquen el secreto o reserva de la información.

Posteriormente, en septiembre de 2006, la Corte Interamericana de Derechos Humanos (en adelante, Corte IDH), condenó al Estado de Chile en el caso Claude Reyes a "adoptar, en un plazo razonable, las medidas necesarias para garantizar el derecho de acceso a la información bajo el

3 REHREN, A. La Evolución de la Agenda de Transparencia en los Gobiernos de la Concertación. Instituto de Ciencia Política UC, Pontificia Universidad Católica de Chile. 2008.

4 Entenderemos por transparencia activa el deber de órganos del Estado de mantener a disposición permanente del público, a través de sus sitios electrónicos, un conjunto de información relevante para la fiscalización de su gestión.

5 Informe Comisión de Constitución del Senado. Historia de la Ley № 20.050. Reforma Constitucional que Introduce Diversas Modificaciones a la Constitución Política de la República. Artículo $1^{\circ}$ número 3 (Principios de probidad y publicidad). 06 de noviembre de 2001. Cuenta en sesión 12, Legislatura 345. Pág. 22 [en línea]. Disponible en: http:// www.bcn.cl/carpeta_temas_profundidad/temas_profundidad.2008-03-18.6305273234/documentos-de-acceso-a-lainformacion-publica/HL20050_art1_N3.pdf; [citado el 12 de enero de 2009] 
control del Estado". Esta sentencia legitimó el concepto de derecho de acceso a la información pública como derecho fundamental, al indicar que "el derecho a la libertad de pensamiento y de expresión contempla la protección del derecho de acceso a la información bajo el control del Estado, el cual también contiene de manera clara las dos dimensiones, individual y social, del derecho a la libertad de pensamiento y de expresión, las cuales deben ser garantizadas por el Estado de forma simultánea" ${ }^{\prime}$.

Estos dos hechos incorporaron y fortalecieron en la discusión político-legislativa la idea de que la legislación sobre el acceso a la información suponía la regulación de un derecho fundamental, en contraste a la histórica idea de su regulación como una herramienta para combatir la corrupción y modernizar el Estado.

En 1996, y en respuesta a una nueva serie de escándalos de corrupción en órganos de la administración del Estado, la Presidenta de la República convocó a un comité de expertos -formado en su mayoría por miembros de la sociedad civil ${ }^{8}-$, a quienes encargó la elaboración de un "informe sobre medidas para favorecer la probidad y eficiencia de la gestión pública". Entre sus recomendaciones, el comité de expertos propuso que se dictara una "ley especial que se encargara de precisar y hacer efectivo el derecho ciudadano de acceso a la información pública". El comité recomendó (i) la limitación de las causales de reserva en conformidad con las normas constitucionales; (ii) la positivización de los principios del acceso a la información reconocidos internacionalmente; (iii) la consagración del deber de transparencia activa; y (iv) la creación de un órgano autónomo con rango constitucional cuya tarea fuese garantizar el acceso a la información pública.

El Ejecutivo incorporó estas recomendaciones a través de una indicación sustitutiva total a la moción del año 2005 patrocinada por los senadores Larraín y Gazmuri ${ }^{9}$ para regular el acceso a la información administrativa. Estos antecedentes dieron forma a la actual Ley $\mathrm{N}^{0} 20.285$ sobre Acceso a la Información Pública y a la Ley de Transparencia de la Función Pública y Acceso a la Información de la Administración del Estado (en adelante, Ley de Transparencia o LT) creada por ella ${ }^{10}$.

6 Corte IDH. Claude Reyes y otros Vs. Chile. Excepciones Preliminares, Fondo, Reparaciones y Costas. Sentencia de 19 de septiembre de 2006, Serie C, № 151. punto 7 de la parte resolutoria y párr. 77, respectivamente.

7 MUÑOZ, A. Transición a la Democracia, Políticas de Probidad y Mecanismos Internacionales de Protección de Derechos Humanos. El Caso de Chile. En: ZALAQUETT J. y MUÑOZ A. Transparencia y Probidad Pública. Estudios de Casos de América Latina, Centro de Derechos Humanos, Universidad de Chile, 2008, pp. 113-129.

8 Esta comisión fue integrada por: Enrique Barros, abogado y profesor universitario; Carlos Carmona, Jefe de la División Jurídica-Legislativa de Ministerio Secretaría General de la Presidencia; Alejandro Ferreiro, Ministro de Economía; Davor Harasic, presidente de Chile Transparente; María Olivia Recart, Subsecretaria de Hacienda; Salvador Valdés, Economista e investigador CEP; y José Zalaquett, abogado, actualmente co-Director del Centro de Derechos Humanos de la Universidad de Chile.

9 Proyecto de Ley sobre Acceso a la Información Pública. Corresponde a la moción de los senadores Hernán Larraín y Jaime Gazmuri. Boletín № 3773.

10 La Ley N o 20.285 sobre acceso a la información pública (LAIP) se compone de once artículos y un artículo transitorio. En su artículo $1^{\circ}$ la LAIP aprueba la "Ley de Transparencia de la Función Pública y Acceso a la Información de la Administración del Estado" (LT), la que consta de 49 artículos y 3 disposiciones transitorias. Es en esta última donde se regula el derecho de acceso a la información, sus principios, las normas de transparencia activa, el procedimiento de acceso a la información y las causales de reserva de la misma y el Consejo para la Transparencia.

Los demás artículos de la LAIP regulan, a partir de remisiones específicas a las normas de la LT, los diferentes regímenes de transparencia que se exigen a otros órganos del Estado (v.gr. órganos autónomo-constitucionales; el Poder judicial; el Congreso Nacional; las empresas públicas; etc.) 


\section{Desafíos del Consejo para la Transparencia y efectiva garantía del derecho de acceso a la información pública en Chile}

No obstante la compleja evolución que ha experimentado el tratamiento y regulación del derecho de acceso a la información pública en Chile, la incorporación en nuestro sistema jurídico del Consejo para la Transparencia, órgano autónomo encargado de promover la transparencia, fiscalizar el cumplimiento de la ley y garantizar el derecho de acceso a la información, permitirá favorecer el desarrollo de una institucionalidad que profundice en la aplicación efectiva de los principios de transparencia y publicidad al interior de los órganos del Estado.

\section{a. Delimitación de las causales de reserva}

La discusión legislativa sobre el acceso a la información en Chile no se desarrolló desde el reconocimiento y regulación de un derecho fundamental. Aun cuando el Tribunal Constitucional en 1995 reconoció el rango constitucional de este derecho ${ }^{11}$, no se generó un cambio en la discusión legislativa, ni se permeó la labor del Poder Ejecutivo o de los tribunales de justicia ${ }^{12}$.

Luego, la eficacia de la LAIP dependerá en gran medida de la forma en que el Consejo para la Transparencia reconozca y fortalezca el derecho de acceso a la información como derecho fundamental. El Consejo debiese orientar decisivamente la labor de las Cortes Apelaciones, órganos que, en última instancia, son llamados a delimitar las causales de reserva de la información al conocer de los reclamos de ilegalidad que los órganos de la administración o los particulares presenten en contra de las resoluciones del Consejo ${ }^{13}$.

Las causales de reserva o secreto de la información establecidas por la Ley de Transparencia son, en general, razonables y se ajustan a los estándares que al efecto se observan en el derecho comparado. Sin embargo, las causales constituyen "conceptos jurídicos indeterminados" cuyo contenido y extensión requiere ser delimitado para su aplicación al caso en concreto.

Al respecto, es probable que un reconocimiento "débil" o restrictivo del derecho de acceso a la información extienda, injustificadamente, el ámbito de reserva de la información; mientras que su reconocimiento "fuerte" como "norma iusfundamental adscrita a la libertad de expresión" (Art. $19 \mathrm{~N}^{\circ} 12 \mathrm{CPR}, 13 \mathrm{CADH}$ y $5^{\circ}$, inciso $2^{\circ} \mathrm{CPR}$ ) lo constituirá en un mandato que obligue a su máxima realización posible ${ }^{14}$.

11 STC Rol No 226 de 30 octubre de 1995. Requerimiento sobre el proyecto de ley sobre libertad de expresión, información y ejercicio del periodismo que fue motivado por diputados de la oposición política quienes consideraban que el proyecto consagraba un derecho que la Constitución no establecía (el derecho de las personas a estar debidamente informadas sobre las distintas expresiones culturales, sociales o políticas existentes en la sociedad -artículo $1^{\circ}$, inciso $3^{\circ}$ ) y, por tanto, no existiría ninguna exigencia constitucional a su regulación. También se reconoce como derecho constitucional en STC Rol N ${ }^{\circ}$ 634-2006, de 9 de agosto de 2007.

12 Al respecto, véase: CONTESSE, J. La Opacidad del Administrador y la indulgencia judicial: Jurisprudencia y práctica sobre acceso a la información pública en Chile. En: Libertad de Expresión en Chile, Universidad Diego Portales, 2006.

13 Según el artículo 28 de la LT, contra de las resoluciones del Consejo que denieguen el acceso a la información pública, procederá el reclamo de ilegalidad ante las Cortes de Apelaciones. Asimismo, dicho artículo faculta a los órganos de la administración a reclamar ante las Cortes de Apelaciones cuando se otorgue el acceso a la información, exceptuando aquellos casos en que la causal invocada por la administración para denegar el acceso haya sido "el debido cumplimiento de las funciones del órgano".

14 Sobre el reconocimiento "débil" del derecho de acceso a la información, las críticas a la tesis del Tribunal Constitucional respecto del acceso a la información como "derecho implícito" en la Constitución y la tesis de un reconocimiento "fuerte" del derecho de acceso a la información como norma iusfundamental adscrita a la Constitución, véase: GARCÍA, G. y CONTRERAS, P. Derecho de Acceso a la Información en Chile: Nueva regulación e implicancias para el sector de la Defensa Nacional. En: Seminario: Acceso a la Información y Derechos Humanos. Santiago, Chile, Universidad Alberto Hurtado, 2008. Inédito. 
Estas causales deberán ser interpretadas para cada caso particular y ponderarse adecuadamente los valores en contraposición: el acceso a la información versus el bien jurídico protegido por cada causal de reserva. La interpretación de estos conceptos jurídicos indeterminados deberá ser restrictiva, conforme con el artículo 19 No 26 CPR y los principios de apertura o transparencia, máxima divulgación y divisibilidad, consagrados en el artículo 11 de la $\mathrm{LT}^{15}$.

La Corte IDH señaló que "el derecho a la libertad de pensamiento y de expresión contempla la protección del derecho de acceso a la información bajo el control del Estado" ${ }^{16}$. Conforme con este pronunciamiento, el Consejo deberá delimitar las causales de reserva considerando que "[...] las restricciones que se impongan deben ser necesarias en una sociedad democrática, lo que depende de que estén orientadas a satisfacer un interés público imperativo. Entre varias opciones para alcanzar ese objetivo, debe escogerse aquella que restrinja en menor escala el derecho protegido. Es decir, la restricción debe ser proporcional al interés que la justifica y debe ser conducente para alcanzar el logro de ese legítimo objetivo, interfiriendo en la menor medida posible en el efectivo ejercicio del derecho"17.

Para efectos de determinar la aplicabilidad de las causales de reserva, uno de los mecanismos que se utiliza mayoritariamente en la doctrina comparada es el denominado "test de daño". Este test establece la obligación de la autoridad de demostrar que la divulgación de un determinado documento o información produce o puede producir un daño específico a un valor o un derecho jurídicamente protegido. Por ejemplo, frente a una solicitud de entrega de un documento relativo a seguridad nacional, no es suficiente que el documento en cuestión trate materias de seguridad nacional para que en forma automática se le otorgue el carácter de reservado. En este caso, corresponde que la autoridad lleve a cabo una ponderación de los valores en conflicto, esto es, el derecho de acceso a la información pública frente a la seguridad nacional, de manera de poder determinar si con motivo del ejercicio del primero de ellos se dañará el segundo y que, como consecuencia de esa ponderación, corresponda aplicar una reserva temporal o no del documento solicitado.

La Ley de Transparencia incorporó el test de daño como uno de los criterios para resolver la aplicación de las excepciones al principio de la publicidad. Al efecto, el artículo 21 de la LT establece la posibilidad de negar el acceso a la información, ya sea total o parcialmente "cuando su publicidad, comunicación o conocimiento afecte...". Esta forma de calificar las excepciones a la publicidad de los documentos en la ley recoge la experiencia de países que cuentan con una desarrollada legislación en la materia como Irlanda, Canadá, Inglaterra y

15 El principio de apertura o transparencia consiste en que toda la información en poder de los órganos de la Administración del Estado se presume pública, a menos que esté sujeta a las excepciones señaladas. Por tanto, se invierte la carga de la prueba en favor del requirente de información, correspondiendo al órgano que niegue su acceso acreditar la causal legal de secreto o reserva en que se funda. Finalmente, por el principio de la divisibilidad, si un acto administrativo contiene información que puede ser conocida y a su vez contiene información que debe denegarse en virtud de causa legal, se mantendrá en reserva sólo aquella parte que se considera reservada.

16 Corte IDH. Caso Claude Reyes vs. Chile, párr. 77.

17 Corte IDH. Caso Claude Reyes vs. Chile, párr. 91. En igual sentido la Comisión Interamericana de Derechos Humanos en su Declaración sobre Libertad de Expresión (108 Período ordinario de sesiones, octubre, 2000) señaló que "[e]l acceso a la información en poder del Estado es un derecho fundamental de los individuos. Los Estados están obligados a garantizar el ejercicio de este derecho. Este principio sólo admite limitaciones excepcionales que deben estar establecidas previamente por la ley para el caso que exista un peligro real e inminente que amenace la seguridad nacional en sociedades democráticas". En similar sentido el Tribunal Europeo de Derechos Humanos ha señalado que la restricción del derecho de acceso a la información debe ser "necesaria" para asegurar un fin legítimo, es decir, que el acceso a la información dañe sustancialmente o perjudique seriamente un interés protegido. Primando el carácter público de la información cuando en la revelación exista un interés superior al de su reserva. Lingens v. Austria, 8 de julio de 1986, solicitud Na 9815/82, EHRR 407. párr. 39-40. 
México. Particularmente la experiencia en el análisis de casos de estos dos últimos países será de especial utilidad, pues éstos sirvieron de modelo para el diseño de la institucionalidad de acceso a la información chilena.

En el caso de México, para efectos de precisar el estándar o criterio en la aplicación del test de daño, el Instituto Federal de Acceso a la Información Pública (IFAI) de México, organismo similar al Consejo para la Transparencia, entregó lineamientos generales para la clasificación y desclasificación de información. El IFAI intentó entregar mayor sustento técnico en la interpretación de la ley mediante la incorporación de elementos objetivos para la determinación del daño por difusión de información. Se estableció que el daño a los intereses establecidos en la ley debía ser "presente, probable y específico". No obstante, la aplicación de este estándar ha sido difícil. El IFAI ha tenido problemas en precisar el contenido específico de daño "presente", "probable" y "específico", y se ha limitado a reiterar lo establecido en la ley y en los lineamientos ya señalados ${ }^{18}$, sin profundizar en los fundamentos y criterios necesarios para delimitar las causales de reserva.

En Inglaterra, la Ley de Libertad de Información ${ }^{19}$ establece 23 excepciones a la publicidad de la información, la mayoría de éstas sujetas al test de daño. Para efectos de fijar el estándar de daño que debe aplicarse a las causales, la legislación inglesa utiliza como criterio "la probabilidad" de que se genere el perjuicio. De esta forma, la autoridad Ilamada a aplicar este estándar deberá ponderar los valores en conflicto evaluando la probabilidad de que ocurra un daño al divulgar la información requerida. En este ejercicio deberían considerarse factores objetivos que permitan advertir la presencia de un perjuicio inminente y muy probable que justifique la excepción de publicidad.

La incorporación en el test de daño de elementos que permitan determinar si la difusión de la información causará un daño específico a los bienes jurídicos tutelados por la ley requerirá del Consejo para la Transparencia una argumentación correcta y persuasiva, particularmente si espera incidir en la incorporación de una sólida construcción dogmática que modifique la actual línea de la jurisprudencia.

Si no se satisface este desafío, las resoluciones del Consejo no generarán la atención pública que una ley de estas características requiere, y sus decisiones estarán permanentemente sujetas a una revisión posterior. Las legislaciones de Inglaterra y México han prevenido este posible inconveniente negando la posibilidad de apelar a resoluciones del órgano autónomo encargado de la fiscalización de la ley, como ocurre con las resoluciones del IFAI ${ }^{20}$; o creando un órgano de apelación autónomo y especializado, como es el caso del Tribunal de Información inglés respecto de la Oficina del Comisionado de Información.

18 LÓPEZ-AYLLÓN, S. y POSADAS, A. Las Pruebas de Daño e Interés Público en Materia de Acceso a la Información. Una Perspectiva Comparada. Derecho Comparado de la Información, № 9. Instituto de Investigaciones Jurídicas, Universidad Nacional Autónoma de México [en línea]. Junio de 2007. Disponible en http://www.juridicas.unam.mx; [citado el 12 de enero de 2009]

19 Ley de Libertad de Información del Reino Unido. Freedom Information Act de 2000.

20 Sin embargo, transcurrido un año desde la resolución del IFAI que confirmó una resolución de la Administración denegatoria del acceso a la información, el solicitante, atendiendo al posible cambio de razón para la denegación, podrá reponer su solicitud para que éste reconsidere su resolución inicial (Art. 60 de la Ley sobre Acceso a la Información Pública Mexicana). 


\section{b. De los diferentes regímenes de transparencia y las deficiencias de la LAIP en materia de transparencia pasiva ${ }^{21}$}

De los once artículos que componen la Ley N² 20.285 sobre Acceso a la Información Pública (LAIP), es el artículo $1^{\circ}$ el que aprueba la "Ley de Transparencia de la Función Pública y Acceso a la Información de la Administración del Estado" (LT). Compuesta por 49 artículos y 3 disposiciones transitorias, la LT regula el derecho de acceso a la información y se aplica sólo a los órganos de la Administración del Estado 22 .

En consecuencia, estos órganos se encuentran obligados por las normas que regulan los principios del derecho de acceso a la información, las normas de transparencia activa y pasiva, las causales de secreto y reserva de la información, y un régimen de sanciones, además de encontrarse sujetos a la competencia del Consejo para la Transparencia. Así, las normas de la Ley de Transparencia constituyen un cúmulo de facultades y deberes al que denominaremos (i) "régimen general de transparencia".

Por su parte, los demás artículos de la LAIP regulan las normas de transparencia que se exigen a los restantes órganos del Estado, siendo posible distinguir además otros dos regímenes de transparencia: uno aplicable a la mayor parte de los órganos autónomo-constitucionales (Contraloría General de la República, el Banco Central y el Ministerio Público), que hace aplicables y obligatorias parte importante de las normas de la Ley de Transparencia (remitiéndose expresamente a ella) y los excluye de la competencia del Consejo para la Transparencia, que denominaremos (ii) "régimen de aplicación restringida de las normas de transparencia"23; y, por último, un (iii) "régimen especial de transparencia" respecto del Poder Judicial, el Congreso Nacional y el conjunto de empresas ligadas al Estado ${ }^{24}$, a los cuales, en principio, sólo se obliga a mantener, a través de sus sitios electrónicos, un conjunto de información a disposición de público, sin perjuicio de otras obligaciones especiales ${ }^{25}$.

Con motivo del pronunciamiento del Tribunal Constitucional ${ }^{26}$ también se incluyó en este régimen especial de trasparencia al Tribunal Constitucional y los Tribunales que conforman la Justicia Electoral; a los que, originalmente, el legislador incluía en el denominado "régimen de aplicación restringida de las normas de transparencia".

Respecto del procedimiento para solicitar información a los órganos de la administración del Estado, la LT en su Título IV reconoce el derecho a solicitar y recibir información en poder de cualquier órgano de la Administración del Estado o elaborada con presupuesto público, establece

21 Entenderemos por transparencia pasiva el procedimiento legal mediante el cual los órganos del Estado responden a los requerimientos de información de los ciudadanos.

22 La LT en su artículo $1^{\circ}$ entiende por órganos de la Administración del Estado los señalados en el artículo $1^{\circ}$, inciso $2^{\circ}$, de la Ley de Bases Generales de la Administración del Estado. Sin perjuicio de las precisiones que efectúa el artículo $2^{\circ}$ de la misma LT.

23 Los artículos $5^{\circ}, 7^{\circ}$ y $9^{\circ}$ de la LAIP hacen aplicables a estos órganos: el principio de transparencia (artículos $3^{\circ}$ y $4^{\circ}$ LT); "en lo que fuere pertinente", las normas que regulan el concepto de información pública (Título II LT); el deber de transparencia activa (artículos $7^{\circ}$ y $9^{\circ} \mathrm{LT}$ ); los principios del derecho de acceso a la información pública (artículo 11 LT), las causales legales de secreto o reserva de la información (artículo 21 LT), la duración de dicho secreto o reserva (artículo 22 LT) y el procedimiento para la solicitud de información (artículos 10 a 22 LT); pero les somete a un procedimiento especial para el reclamo por la denegación del acceso a la información ante las Cortes de Apelaciones, excluyéndolos de la competencia del Consejo para la Transparencia.

24 Empresas públicas creadas por ley, empresas del Estado y las sociedades en que éste tenga participación accionaría superior al $50 \%$ o mayoría en el directorio (Art. $10^{\circ}$ LAIP).

25 Artículos $6^{\circ}, 8^{\circ}$ y $10^{\circ}$ de la LAIP.

26 STC Rol No 1051, 10 de julio de 2008. 
los principios que orientan la interpretación de este derecho y las normas procesales que aseguran su tutela, modifica antiguos errores que restringían arbitrariamente su ejercicio ${ }^{27}$ e instituye un nuevo procedimiento para hacer efectivo el acceso a la información pública. En virtud de este procedimiento, el Consejo para la Transparencia, como órgano especializado y autónomo, conoce en primera instancia de los reclamos por la denegación del acceso a la información, y la Corte de Apelaciones respectiva resuelve los reclamos de ilegalidad contra las resoluciones del Consejo.

Sin perjuicio de lo anterior, esta moderna legislación sólo se aplica a cabalidad a los órganos de la Administración del Estado, pues el legislador dejó fuera del ámbito de competencia -o jurisdicción- del Consejo a los órganos autónomo-constitucionales precitados (probablemente previniendo dudas sobre la constitucionalidad de su inclusión). Luego, las personas que deseen reclamar la violación de su derecho al acceso a la información por parte de estos órganos deberán hacerlo ante las Cortes de Apelaciones.

Por su parte, inexplicablemente, el legislador excluyó de la aplicación de estas reglas generales y restringidas al Congreso Nacional y al Poder Judicial, "siendo imposible encontrar en los registros de los debates o en la iniciativa del proyecto alguna justificación a este trato diverso que se brinda a diversos órganos igualmente autónomos respecto de las obligaciones a que quedan sometidos para cumplir con el principio de transparencia" 28 .

A mayor abundamiento, el propio Tribunal Constitucional determinó que, junto con la Justicia Electoral, debían ser eximidos de un procedimiento de revisión de sus resoluciones sobre acceso a la información, cuya competencia se entregaba a las Cortes de Apelaciones. Lo anterior pues someter sus resoluciones o determinaciones en materia de acceso a información al escrutinio de un tribunal ordinario de justicia subalterno de la Corte Suprema era contrario a la autonomía constitucional que consagra el artículo 82 de la Carta Fundamental, el cual establece que ambos órganos se encuentran al margen de la superintendencia directiva, correccional y económica de la Corte Suprema 29.

En consecuencia hoy, por una parte, no existe procedimiento legal alguno para "solicitar" información ni para "reclamar" por su denegación cuando este derecho sea ejercido ante el Congreso Nacional, el conjunto de empresas ligadas al Estado, los tribunales que forman parte del Poder Judicial y otros tribunales especiales; y, por otra parte, no existe procedimiento legal para "recla-

27 Como ocurría con la Ley de Bases Generales de la Administración del Estado al permitir la denegación de la información por la oposición "sin expresión de causa" de aquellos terceros que supuestamente se verían afectados por la publicidad de la información.

28 STC Rol No 1051-2008. Voto disidente de los Ministros Hernán Vodanovic Schnake y Jorge Correa Sutil. Párr. 1. p. 77.

29 STC Rol № 1051-2008, cons. 46. Sobre el particular, en concordancia con el voto disidente del Tribunal Constitucional (Ministros Vodanovic y Correa), creemos que esta sujeción al control de las Cortes de Apelaciones en materias de acceso a la información no supone una vulneración de su autonomía constitucional pues si bien sujetarlos al control heterónomo de otro órgano del Estado "irá en desmedro de su autonomía, no les afecta en el cumplimiento de aquellas funciones que les son propias y que la Carta Fundamental les encarga", pues "tal autonomía no equivale a una autarquía absoluta en todas sus decisiones y ciertamente no se contrapone a que la Constitución y la ley puedan establecer, dentro de límites, un control interórganos, en materias que no sean las propias de su competencia constitucional o esencial". A lo que debe agregarse que esta "limitación a la autonomía persigue, a su vez, una finalidad que (al igual que la autonomía) también tiene jerarquía constitucional, como es la transparencia, bien que aparece instituido entre las bases esenciales del ordenamiento jurídico chileno. Los poderes colegisladores han decidido que el valor de la transparencia debe alcanzarse aun a costa de que órganos constitucionalmente autónomos se sometan a un control externo, en esta sola materia y con los alcances ya referidos" (voto disidente Ministros Vodanovic y Correa, párr. 5. p. 80). Por lo demás, resulta cuestionable considerar que la revisión por parte de las Cortes de Apelaciones de las decisiones adoptadas por estos órganos supongan una sujeción a la superintendencia de la Corte Suprema cuando la competencia de estas Cortes en materia de acceso a la información parece adecuarse más a la resolución de una materia jurisdiccional -amparo de derechos fundamentales- que a una de tipo administrativa o directiva, en la que sí estaría presente la superintendencia de la Corte Suprema. 
mar" por la denegación de acceso a la información que efectúen el Tribunal Constitucional y la Justicia Electoral.

En estos casos, la ausencia de un procedimiento legal que asegure la efectiva tutela del derecho fundamental de acceso a la información es incompatible con el deber de todos los órganos del Estado de respetar, garantizar y promover el ejercicio de los derechos fundamentales. Debemos recordar que "[e]l derecho a acceder a las informaciones que obran en poder de los órganos del Estado forma parte de la libertad de expresión que se encuentra consagrada en el artículo 19, $\mathrm{N}^{0} 12$ de la Carta Fundamental" ${ }^{30}$. Por tanto, es deber de los órganos sujetos al régimen especial de transparencia crear los mecanismos y procedimientos que aseguren el ejercicio de este derecho fundamental, excluyendo toda exigencia o requisitos que puedan obstruir o impedir su ejercicio $^{31}$.

Sobre el particular, estos órganos del Estado "podrán considerar" las normas generales que al efecto dicte el Consejo para la Transparencia, sin encontrarse obligados a adoptarlas ${ }^{32}$. La relación del Consejo con estos órganos será un importante desafío, toda vez que sólo a través de la solidez jurídica de sus recomendaciones y de su reconocimiento ciudadano le será posible influir en la normativa interna de estos órganos autónomo-constitucionales.

Resulta preocupante la visión que ha expresado el Tribunal Constitucional cuando, en una determinación restrictiva de las exigencias del principio de transparencia y publicidad constitucional, señaló que el debido acatamiento del principio consagrado en el artículo $8^{\circ}$ de la Constitución por el propio Tribunal Constitucional y de la Justicia Electoral "se satisface adecuadamente con la divulgación de sus resoluciones jurisdiccionales y de otros antecedentes relevantes de su quehacer, en los términos que contempla el artículo $7^{\circ}$ de la Ley de Transparencia de la Función Pública y de Acceso a la Información de la Administración del Estado (transparencia activa), que el mismo artículo noveno del proyecto en examen hace aplicable a esos órganos" ${ }^{\prime 33}$. Este pronunciamiento pasó por alto la relevancia de instituir procedimientos que garanticen, al interior de cada órgano, el ejercicio del derecho de acceso a la información. En el caso que esta interpretación sea compartida por otros órganos del Estado que se encuentran en una situación similar, podría debilitarse profundamente el ejercicio de este derecho.

Con todo, será posible ejercer la acción de protección respecto de los actos u omisiones de aquellos órganos que no se encuentran regulados por un procedimiento especial de acceso a la información cuando ésta se deniegue de forma injustificada, por no ajustarse a las causales constitucionales de reserva de la información establecidas en el artículo $8^{\circ}$ de la Constitución Política, o por la imposición de cualquier condición, tributo o requisito que impida su libre ejercicio $(\mathrm{Vg}$. Demoras excesivas en su tramitación o costos excesivos). Sin embargo, los resultados de esta acción consti-

30 STC Rol Nº 634-2006, cons. 9.

31 En ese sentido la Corte Interamericana consideró necesario "reiterar que, de conformidad con el deber dispuesto en el artículo 2 de la Convención, el Estado tiene que adoptar las medidas necesarias para garantizar los derechos protegidos en la Convención, lo cual implica la supresión tanto de las normas y prácticas que entrañen violaciones a tales derechos, así como la expedición de normas y el desarrollo de prácticas conducentes a la efectiva observancia de dichas garantías". Corte IDH. Caso Claude Reyes Vs. Chile, párrs. 100-101.

32 El Tribunal Constitucional ha declarado que cuando la LAIP establece que los órganos autónomo-constitucionales deberán "considerar" las instrucciones del Consejo, ello "implica sólo estimar, evaluar o ponderar, pero de ningún modo hacer vinculantes u obligatorias las resoluciones de aquél en relación a los señalados organismos del Estado". Respecto del Congreso Nacional y el Poder Judicial, la LAIP no establece norma alguna sobre del papel del Consejo respecto de ellos, aunque estos siempre podrán "considerar" sus recomendaciones. STC Rol No 1051-2008, cons. 52-54.

33 Ídem, cons. 46. 
tucional parecen poco auspiciosos cuando se reclame contra actos o resoluciones de los mismos tribunales que integran el Poder Judicial o aquellos que resuelva el Tribunal Constitucional.

\section{c. Implicancias de la naturaleza jurídica del Consejo para la Transparencia}

En base a los antecedentes aportados en la discusión legislativa de la LAIP y el pronunciamiento del Tribunal Constitucional sobre la misma, es posible concluir que la configuración actual del Consejo para la Transparencia, caracterizada por su particular función de fiscalización y sanción, lo convierte en un organismo que forma parte de la Administración del Estado con carácter sui generis ${ }^{34}$.

El Consejo tiene una serie de características ${ }^{35}$ que fortalecen su autonomía: es una "corporación autónoma de derecho público"; cuyo órgano superior es compuesto por cuatro consejeros designados por el Presidente de la República con acuerdo del Senado; su personal se rige por el Código del Trabajo; y "sus resoluciones están exentas de la toma de razón".

Una de las principales implicancias de la peculiar naturaleza jurídica de este Consejo guarda relación con sus atribuciones jurisdiccionales y normativas y su potestad sancionadora. La posible inconstitucionalidad de las potestades jurisdiccionales ${ }^{36}$ y normativas ${ }^{37}$ del Consejo fue discutida al interior del Tribunal Constitucional, lo que finalmente se resolvería en favor de su constitucionalidad.

Respecto de las facultades sancionadoras, la Ley de Transparencia señala en el artículo 49 que las sanciones serán aplicadas por el Consejo previa investigación sumaria o sumario administrativo, ajustándose a las normas del Estatuto Administrativo. Además, cuando el Consejo lo solicite, la Contraloría General de la República, de conformidad con las normas de su ley orgánica, podrá incoar el sumario y establecer las sanciones que correspondan. El Estatuto Administrativo sólo regula la determinación e imposición de sanciones administrativas a los miembros del personal de las reparticiones de la Administración que se señalan en su artículo $1^{\circ}$, esto es, ministerios, intendencias, gobernaciones y los servicios públicos centralizados y descentralizados creados para el cumplimiento de la función administrativa. Luego, no está claramente definido cuál es el procedimiento de ejecución de las sanciones de las resoluciones del Consejo para la Transparencia (que por aplicación del principio de legalidad -propio del derecho administrativo sancionadorla ley debería contener $\mathrm{o}$, al menos, remitirse a uno preexistente) respecto de organismos a los cuales no se les aplica el Estatuto Administrativo, como es el caso de las Municipalidades y Fuerzas

34 RAJEVIC, E. Una nueva vuelta de tuerca en materia de acceso a la información: la ley 20.285. [en línea]. Septiembre de 2008. Disponible en http://decive.blogspot.com/2008/09/una-nueva-vuelta-de-tuerca-en-materia.html [citado el 12 de enero de 2009]. Véase también Informe de la Comisión Mixta de 14 de enero, 2008. Cuenta en Sesión 82, Legislatura 355, Senado. STC Rol No 1051-2008, cons. 37 y 52.

35 Sobre las características del Consejo que determinan que este sea o no considerado un servicio público, véase la intervención del diputado Jorge Burgos en la Sala de la H. Cámara de Diputados. Diario de Sesiones de la H. Cámara de Diputados. Legislatura 355a , Sesión 136 a Jueves 17 de enero de 2008.

36 Los Ministros Venegas y Navarro en su voto de indicaron que "en su opinión, no resulta constitucionalmente aconsejable que potestades ciertamente jurisdiccionales sean entregadas a órganos que no tengan el carácter de tribunales de justicia (Artículo 38 CPR) y que, por el contrario, formen parte de la Administración del Estado a la que precisamente deben juzgar, como sucede en la especie con el Consejo para la Transparencia". STC Rol № 1051-2008. Voto disidente de los Ministros Marcelo Venegas Palacios y Enrique Navarro Beltrán, párr. 3. p. 75.

37 El voto de minoría de los Ministros Bertelsen y Correa, argumento en favor de la declaración de inconstitucionalidad del artículo 33, letra b), de la Ley de Transparencia, señalando que la atribución del Consejo para dictar instrucciones generales a los órganos de la Administración del Estado era contraria al artículo 24 de la Constitución, relativo a la potestad del Presidente de la República para Administrar al Estado y al carácter democrático de la República de Chile por entregar esta función a un órgano no electo y sin responsabilidad política. STC Rol № 1051-2008. Voto disidente de los Ministros Raúl Bertelsen Repetto y Jorge Correa Sutil, párr. único. p. 76. 
Armadas, de Orden y Seguridad Pública, pues estos quedarían fuera del ámbito de aplicación de esta normativa.

\section{Conclusiones}

La LAIP es una normativa moderna y que cumple con los más avanzados estándares internacionales en la materia, por lo que responde a las exigencias ciudadanas y a las de los órganos internacionales de garantizar adecuadamente el derecho de acceso a la información. Sin perjuicio de lo anterior, su aprobación obedece más a una respuesta gubernamental a escándalos de corrupción, que a una profunda convicción de los actores políticos acerca de la importancia del acceso a la información. Es por ello que la implementación de la ley enfrentará numerosos desafíos para contrarrestar la actual cultura de secretismo que impera en el sector público chileno. El Consejo para la Transparencia deberá desempeñar un rol crucial en este cambio de perspectiva.

El Consejo para la Transparencia deberá abordar tres importantes desafíos. En primer lugar, deberá definir los límites del derecho del acceso a la información al determinar los alcances de las causales de reserva establecidas en esta ley. La consistencia argumentativa del Consejo será determinante si espera influir en la jurisprudencia de las Cortes de Apelaciones, instancia que resolverá finalmente las reclamaciones presentadas en contra de las decisiones del Consejo.

En segundo lugar, el Consejo para la Transparencia deberá dar una respuesta coherente a pesar de los diferentes regímenes de transparencia pasiva establecidos por la LAIP, dentro de los cuales existen órganos que quedan fuera de su tutela. Especialmente complejo será resolver los casos de negación de acceso a la información en el Poder Legislativo, Judicial, Tribunal Constitucional y Justicia Electoral, en que la LAIP no estableció mecanismo de reclamación alguno.

Finalmente, el Consejo deberá responder las dudas que genera su propia y excepcional naturaleza jurídica en los procedimientos aplicables en el ejercicio de su rol sancionador respecto de determinados órganos. 